\title{
Prediction of Cytokine Storm and Mortality in Patients with COVID-19 Admitted to ICU: Do Markers Tell the Story?
}

\author{
Rashid Nadeem ${ }^{a} \quad$ Ashraf Mahmoud Elhoufi $^{\mathrm{a}}$ Naheed Elahi lqbal ${ }^{\mathrm{a}}$ \\ Zainab Abdulameer Obaida a Doaa Mohamed Elgohary ${ }^{a}$ Mukesh Kumar Singh ${ }^{a}$ \\ Shymaa Farouk Zoraey ${ }^{a}$ Rami M. Abdalla ${ }^{a}$ Sara Yousif Eltayeb ${ }^{c}$ Crystal Sharon Danthi ${ }^{\text {b }}$ \\ Nouha Azaza ${ }^{c}$ Waleed Mohamed Ahmed ${ }^{c}$ Muzammil Hafeez ${ }^{d}$ Maryam AlSada ${ }^{b}$ \\ Fatima Farid $\mathrm{Mir}^{\mathrm{b}}$ \\ antensive Care Unit, Dubai Hospital, Dubai Health Authority, Dubai, UAE; bPediatrics Department, Dubai Hospital, \\ Dubai Health Authority, Dubai, UAE; Internal Medicine Department, Dubai Hospital, Dubai Health Authority, Dubai,

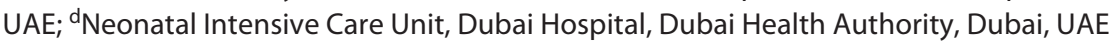

\section{Keywords \\ Critical · Infectious · Inflammatory markers · Medicine}

\begin{abstract}
Introduction: COVID-19 has caused approximately one million deaths worldwide as of November 24, 2020. Markers of disease activity like ferritin, C-reactive protein (CRP), and Ddimers are frequently monitored to detect the best opportunity for intensive treatment. Methods: All patients of $>18$ years of age were included. The primary variables of interest, ferritin, CRP, and D-dimers, for each patient throughout hospitalization were recorded. Primary clinical outcomes of length of stay in ICU and survival were recorded. Demographics: age, gender, $\mathrm{BMI}$, and nationality. Ferritin, CRP, and D-dimers were recorded daily if available for the whole ICU stay, and all other variables were recorded on admission day to ICU. Results: The sample includes 235 records. More than $95 \%$ of patients have all markers on the day of admission to ICU were ferritin (median 1,278; IQR 1,424), D-dimer 1.21 (3.4), and CRP 129.5 (121). Daily average levels of markers were different from their admission day level: ferritin 1,395 (1,331), D-dimer 3.11 (5.52), and CRP 107 (75.8). Multiple logistic regression analysis determined that average CRP
\end{abstract}

karger@karger.com www.karger.com/dmj

Karger $\stackrel{\text { ' }}{5}$
(C) 2021 The Author(s)

Published by S. Karger AG, Basel

This article is licensed under the Creative Commons AttributionNonCommercial-NoDerivatives 4.0 International License (CC BYNC-ND) (http://www.karger.com/Services/OpenAccessLicense) Usage and distribution for commercial purposes as well as any distribution of modified material requires written permission. during the stay was the only predictor of survival. Discussion: Data on markers utilization to detect the acute phase of inflammation help clinicians focus on the opportunity window for intensive treatment. Conclusion: Average CRP during the stay in ICU is higher than CRP on admission. Average CRP is the only factor that predicts survival.

(C) 2021 The Author(s)

Published by S. Karger AG, Basel

\section{Introduction}

COVID-19 has caused a million deaths as of November 24, 2020, worldwide [1]. COVID-19 (SARS CoV-2) spread rapidly via person to person contact and infect predominantly the pulmonary system [2]. Approximately $15 \%$ developed respiratory failure from ARDS, requiring mechanical ventilation and admission to ICU [3]. Progression to ARDS is unpredictable as the disease activity and intensity of inflammation is variable [4]. Therapy timing of anti-inflammatory agents and immune-suppressing medication is of utmost importance. This inflammation is dynamic in COVID-19 and most people get anti-inflammatory treatment, either from the beginning as a standard protocol or with the inflammatory markers monitoring 
Fig. 1. K-P survival plot for ferritin level on admission.

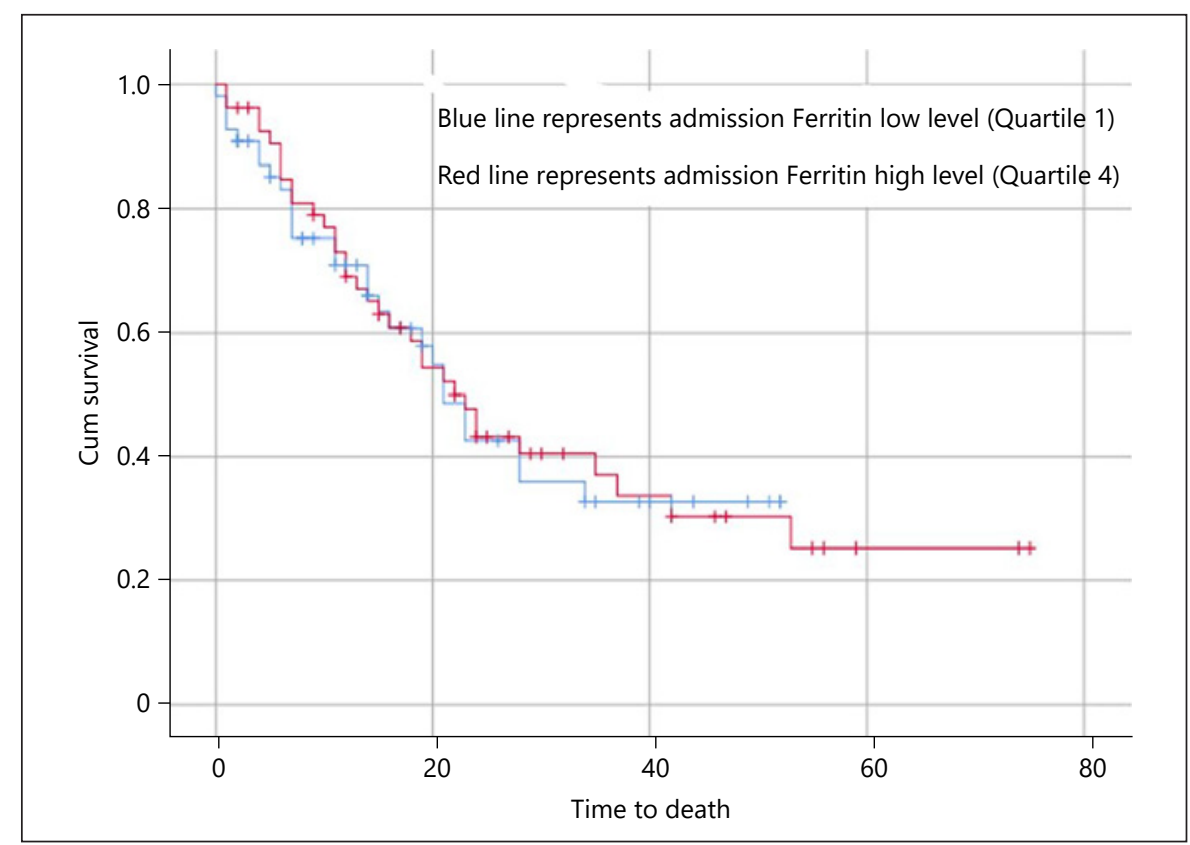

Table 1. Sample characteristics (categorical variables)

\begin{tabular}{lcccc}
\hline Categorical variable & $\begin{array}{l}\text { Total } \\
(N=235)(\%)\end{array}$ & $\begin{array}{l}\text { Alive } \\
(N=116)(\%)\end{array}$ & $\begin{array}{l}\text { Died } \\
(N=119)\end{array}$ & $p$ value* \\
\hline Gender (male) & $206(87.6)$ & $100(86)$ & $106(89)$ & 0.30 \\
Nationalities (expatriates) & $229(97.4)$ & $113(97.4)$ & $116(97.4)$ & 0.60 \\
Diabetes, $N$ (\%) & $101(42.9)$ & $53(45.6)$ & $48(40.3)$ & 0.20 \\
Hypertension (yes) & $58(24.6)$ & $27(23.2)$ & $31(26)$ & 0.30 \\
CAD (yes) & $18(7.6)$ & $4(3.4)$ & $12(10)$ & 0.03 \\
Prior renal impairment (yes) & $28(11.9)$ & $7(6)$ & $21(17.6)$ & 0.01 \\
Outpatient dialysis (yes) & $16(6.8)$ & $6(5.1)$ & $10(8.4)$ & 0.24 \\
Tachycardia on admission (yes) & $184(78.2)$ & $84(72.4)$ & $100(84)$ & 0.02 \\
Hypotension on admission (yes) & $117(49.7)$ & $47(40.5)$ & $70(58.8)$ & 0.01 \\
Mechanical ventilation (yes) & $200(85.1)$ & $96(82.7)$ & $104(87.3)$ & 0.20 \\
Vasopressors use (yes) & $186(79.1)$ & $84(72.4)$ & $102(85.7)$ & 0.01 \\
Dialysis required (yes) & $71(30.2)$ & $21(18.1)$ & $50(42)$ & 0.01 \\
Bacterial infection (yes) & $121(51.4)$ & $57(49.1)$ & $64(53.7)$ & 0.28 \\
Bacteremia (yes) & $94(40)$ & $41(35.3)$ & $53(44.5)$ & 0.11 \\
Chloroquine (yes) & $207(88)$ & $108(93.1)$ & $99(83.1)$ & 0.02 \\
Lopinavir/ritonavir (yes) & $85(36.1)$ & $34(29.3)$ & $51(42.8)$ & 0.01 \\
Favipiravir (yes) & $187(79.5)$ & $102(87.9)$ & $85(71.4)$ & 0.01 \\
Steroids (yes) & $212(90)$ & $110(94.8)$ & $102(85.7)$ & 0.01 \\
Received GI prophylaxis (yes) & $225(95.7)$ & $112(96.5)$ & $113(94.9)$ & 0.37 \\
\hline
\end{tabular}

CAD, coronary artery disease. ${ }^{*} \chi^{2}$ test to assess the difference between groups.

[5]. Optimal administration may prevent cytokine storms and abate the development of ARDS [6]. Markers of disease activity like ferritin, C-reactive protein (CRP), and $\mathrm{D}$-dimers are frequently monitored to detect the best opportunity for intensive treatment [7]. Less commonly lev- els of interleukin 6 are used to detect and target the most intensive part of the disease phase although this test is expensive and only rarely available [8]. It may not be costeffective for the developing world. Hence, identification of intense activity of virus and inflammation is of utmost 
Fig. 2. K-P survival plot for average ferritin during ICU stay.

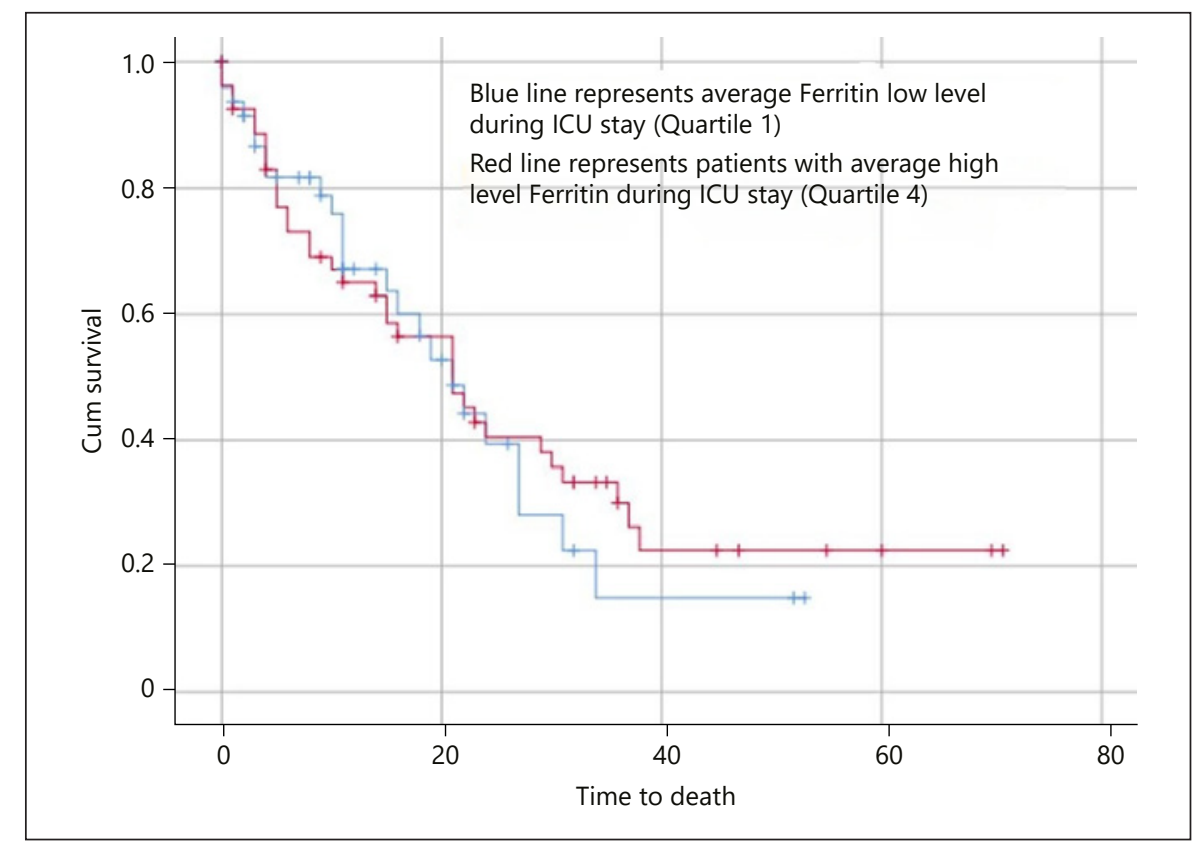

Table 2. Sample characteristics (continuous variables)

\begin{tabular}{|c|c|c|c|c|c|c|c|}
\hline Continuous variable & $\begin{array}{l}\text { Total } \\
(N=235) \\
\text { median }\end{array}$ & IQR & $\begin{array}{l}\text { Alive } \\
(N=116) \\
\text { median }\end{array}$ & IQR & $\begin{array}{l}\text { Died } \\
(N=119) \\
\text { median }\end{array}$ & IQR & $p$ value $\urcorner$ \\
\hline Age, years & 49 & 13 & 49 & 14 & 48.5 & 16 & 0.38 \\
\hline BMI, $\mathrm{kg} / \mathrm{m}^{2}$ & 27.6 & 6.17 & 27.3 & 7.3 & 28.1 & 5.26 & 0.03 \\
\hline Days to seroconversion & 13 & 17 & 18 & 19 & 9 & 15 & 0.01 \\
\hline Ferritin admission, ng/mL & 1,278 & 1,424 & 1,315 & 1,667 & 1,352 & 1,204 & 0.34 \\
\hline Ferritin (average in ICU stay), $\mathrm{ng} / \mathrm{mL}$ & 1,395 & 1,331 & 1,209 & 1,102 & 1,665 & 1,605 & 0.01 \\
\hline D-dimer, ng/mL & 1.21 & 3.4 & 1.14 & 2.85 & 1.8 & 5 & 0.04 \\
\hline $\mathrm{D}$-dimer (average in ICU stay), $\mathrm{ng} / \mathrm{mL}$ & 3.11 & 5.52 & 2.42 & 4.19 & 3.74 & 7.1 & 0.01 \\
\hline $\mathrm{CRP}, \mathrm{mg} / \mathrm{L}$ & 129 & 121 & 132 & 147 & 128 & 101 & 0.64 \\
\hline CRP (average in ICU stay), $\mathrm{mg} / \mathrm{L}$ & 107 & 75.8 & 81.2 & 54.8 & 135 & 87.4 & 0.01 \\
\hline Procalcitonin, ng/mL & 0.34 & 0.59 & 0.34 & 0.55 & 0.29 & 0.77 & 0.11 \\
\hline $\mathrm{Cr}, \mathrm{mg} / \mathrm{dL}$ & 0.9 & 0.35 & 0.9 & 0.3 & 0.9 & 0.85 & 0.01 \\
\hline $\mathrm{CPK}$, units/L & 231 & 616 & 207 & 577 & 310 & 623 & 0.04 \\
\hline ABG PH & 7.37 & 0.13 & 7.40 & 0.13 & 7.37 & 0.15 & 0.78 \\
\hline $\mathrm{PCO}_{2}$, Torr & 37.3 & 15.4 & 36.5 & 15.4 & 38.1 & 14.97 & 0.69 \\
\hline $\mathrm{PO}_{2}$, Torr & 62.6 & 35.1 & 64.2 & 41.3 & 64.9 & 26 & 0.89 \\
\hline Lactate, $\mathrm{mmol} / \mathrm{L}$ & 1.7 & 1.1 & 1.5 & 1.1 & 1.85 & 1.4 & 0.03 \\
\hline Bicarbonate, $\mathrm{mEq} / \mathrm{L}$ & 21.6 & 5.3 & 22.5 & 4.7 & 22.1 & 5.7 & 0.74 \\
\hline Magnesium, mg/dL & 2.04 & 0.36 & 2.04 & 0.37 & 2.06 & 0.35 & 0.46 \\
\hline Platelets, $10^{3} / \mathrm{mL}$ & 203 & 111 & 213 & 119 & 189 & 86 & 0.05 \\
\hline Days on mech. vent & 11 & 19 & 16 & 20 & 16.5 & 19 & 0.13 \\
\hline LOSICU, days & 14 & 22 & 20.5 & 23 & 17 & 18 & 0.07 \\
\hline LOSH, days & 19 & 29 & 36.5 & 31 & 20 & 21 & 0.01 \\
\hline APACHE 2 scores & 16 & 7 & 15 & 7 & 16 & 9 & 0.02 \\
\hline
\end{tabular}

CRP, C-reactive protein; CPK, Cr phosphokinase; LOSICU, length of stay in the intensive care unit. $\urcorner$ Median test $p$ value. 
Fig. 3. K-P survival plot for D-dimer level on admission.

Fig. 4. K-P survival plot for average D-dimer during ICU stay.
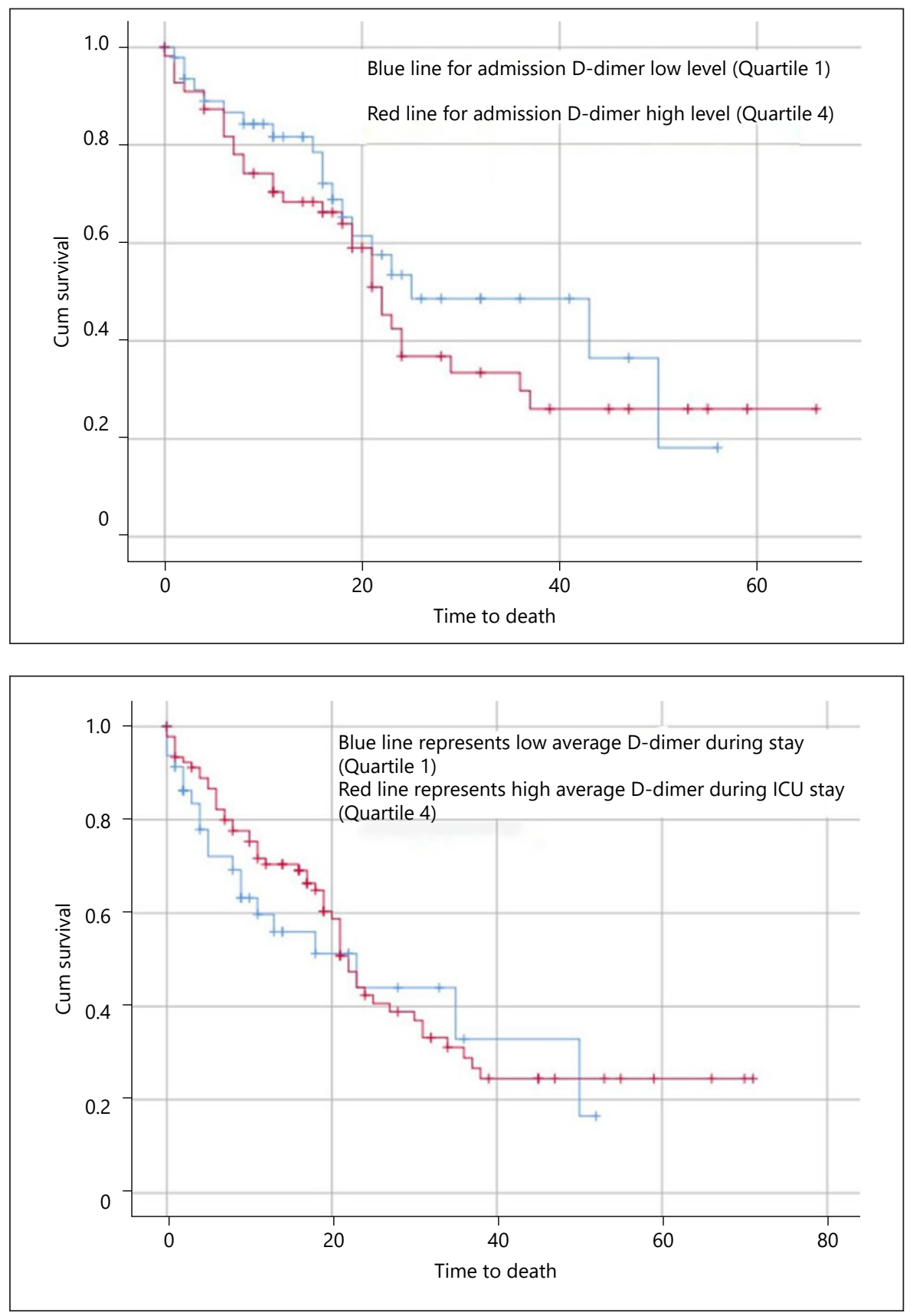

importance. Viral load monitoring is impractical. Inflammatory markers' effectivity for disease monitoring and success of treatment and their cost-effectiveness is important and largely unknown.

Aims: We aim to measure the pattern of these markers' usage, their relationship with the disease and with each other, and their prediction of disease activity and utility for treatment success and clinical outcomes. Moreover, we aim to detect the most active phase of the disease if one exists.

\section{Methods}

All patients with confirmed COVID-19 admitted to ICU of Dubai Hospital between January 1, 2020, and June 30, 2020, were included. We excluded patients $<18$ years of age. The primary variable of interest, ferritin, CRP, and D-dimers, on admission to ICU and for each patient throughout the hospitalization were also recorded. Primary clinical outcomes of length of stay in the intensive care unit (LOSICU) and survival were also recorded. Demographics: age, gender, BMI, and nationality. Comorbidities: diabetes, hypertension, coronary artery disease $(\mathrm{CAD})$, renal failure, and out- 
Table 3. Logistic regression analysis (predictors of survival)

\begin{tabular}{|c|c|c|c|c|c|}
\hline \multirow[t]{2}{*}{ Variables } & \multirow[t]{2}{*}{ B } & \multirow[t]{2}{*}{ Odds ratio* } & \multicolumn{2}{|c|}{$95 \%$ CI for odds ratio } & \multirow[t]{2}{*}{$p$ value } \\
\hline & & & lower & upper & \\
\hline Age (years) & 0.049 & 1.050 & 0.952 & 1.158 & 0.329 \\
\hline Gender (male/female) & -1.076 & 0.341 & 0.024 & 4.825 & 0.426 \\
\hline $\mathrm{BMI}, \mathrm{kg} / \mathrm{m}^{2}$ & 0.005 & 1.005 & 0.933 & 1.083 & 0.892 \\
\hline Days swab test turns negative & -0.175 & 0.840 & 0.754 & 0.935 & 0.001 \\
\hline Diabetes & -0.291 & 0.747 & 0.151 & 3.707 & 0.722 \\
\hline Hypertension & 0.444 & 1.559 & 0.126 & 19.268 & 0.729 \\
\hline CAD & -2.358 & 0.095 & 0.000 & 28.265 & 0.417 \\
\hline Dialysis (outpatient) & 1.150 & 3.158 & 0.143 & 69.724 & 0.466 \\
\hline Mechanical ventilation & -1.765 & 0.171 & 0.002 & 14.335 & 0.435 \\
\hline Vasopressers & 0.902 & 2.464 & 0.017 & 355.829 & 0.722 \\
\hline Bacterial infection & 2.103 & 8.193 & 0.927 & 72.388 & 0.058 \\
\hline Chloroquine & -1.468 & 0.230 & 0.010 & 5.532 & 0.365 \\
\hline Lopinavir/ritonavir & 2.106 & 8.216 & 0.998 & 67.629 & 0.050 \\
\hline Favipiravir & -0.741 & 0.477 & 0.030 & 7.697 & 0.602 \\
\hline Steroids & -2.688 & 0.068 & 0.002 & 2.699 & 0.152 \\
\hline Ferritin, ng/mL & 0.000 & 1.000 & 0.999 & 1.001 & 0.833 \\
\hline D-dimer, ng/mL & 0.016 & 1.016 & 0.936 & 1.102 & 0.708 \\
\hline Procalcitonin, $\mathrm{ng} / \mathrm{mL}$ & -0.103 & 0.902 & 0.556 & 1.464 & 0.676 \\
\hline $\mathrm{CRP}, \mathrm{mg} / \mathrm{L}$ & -0.002 & 0.998 & 0.989 & 1.008 & 0.756 \\
\hline $\mathrm{Cr}$ & -0.133 & 0.875 & 0.526 & 1.456 & 0.608 \\
\hline Cr phosphokinase & 0.000 & 1.000 & 0.999 & 1.001 & 0.560 \\
\hline $\mathrm{ABG} P H$ & -4.947 & 0.007 & 0.000 & 93.309 & 0.307 \\
\hline $\mathrm{PCO}_{2}$, Torr & -0.010 & 0.990 & 0.894 & 1.095 & 0.841 \\
\hline $\mathrm{PO}_{2}$, Torr & 0.017 & 1.017 & 1.001 & 1.033 & 0.032 \\
\hline Platelets $\left(10^{3} / \mathrm{mL}\right)$ & -0.003 & 0.997 & 0.986 & 1.009 & 0.654 \\
\hline APACHE 2 score & -0.116 & 0.891 & 0.766 & 1.036 & 0.133 \\
\hline Average ferritin in ICU stay & 0.000 & 1.000 & 1.000 & 1.000 & 0.599 \\
\hline Average D-dimer in ICU stay & -0.015 & 0.985 & 0.805 & 1.205 & 0.885 \\
\hline Average CRP in ICU stay & 0.029 & 1.030 & 1.010 & 1.050 & 0.003 \\
\hline
\end{tabular}

CAD, coronary artery disease; CRP, C-reactive protein. * For all categorical variables, odds ratios are for presence versus absence of the variable.

patient dialysis were recorded. Immune status, smoking status, and alcohol use were also recorded. Inpatient clinical evaluation details including vital signs, fever, tachycardia, blood pressure, hypoxia, use of mechanical ventilation, use of pressers, or dialysis were also recorded. Laboratory parameters for evidence of infection: WBC and bacteremia were also recorded. Therapy on admission: chloroquine, antivirals, and steroids were recorded. The APACHE 2 scores calculated within $24 \mathrm{~h}$ of admission to ICU were recorded to assess the severity of illness. Ferritin, CRP, and D-dimers were recorded daily if available for the whole ICU stay, and all other variables were recorded on admission day to ICU.

\section{Statistical Analysis}

All the variables were analyzed and found that they were not normally distributed; therefore, median with interquartile ratios was calculated. The average level of the marker was determined by adding all values available and dividing by the number of days values available. $\chi^{2}$ test was performed to detect the difference between variables if they were categorical, and median test was performed if the variable was continuous. For survival analysis, mul- tiple logistic regression was performed with survival (mortality) as dependent variables and all other variables as independent predictors.

Since LOSICU is very skewed and the variance of LOSICU across the levels of CRP was heterogeneous, data were transformed into $\log$ LOSICU and least square regression was performed for log LOSICU and markers (CRP) only for survivors. We used IBM SPSS Statistics for Windows, version 26 (IBM Corp., Armonk, NY, USA).

\section{Results}

Characteristics of the sample $N=235$ are described in Tables 1 and 2 . More than $95 \%$ of patients have all markers on the day of admission to ICU. Average levels of markers were different from their admission day level which suggest levels were changing. Multiple logistic re- 
Fig. 5. K-P survival plot for CRP level on admission. CRP, C-reactive protein.
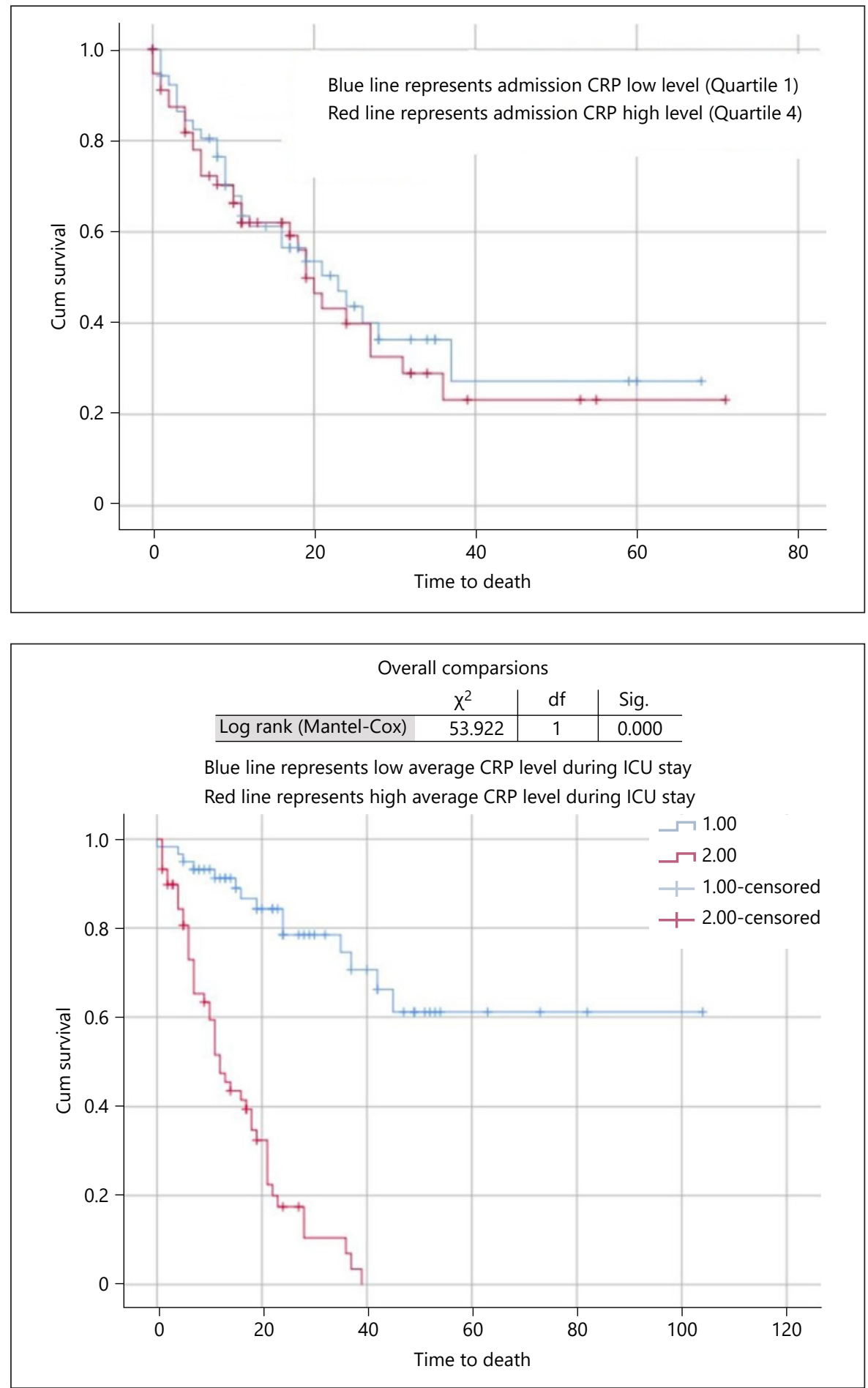

Fig. 6. K-P survival plot for average CRP during ICU stay. CRP, C-reactive protein.

gression model showed only elevated average CRP during ICU stay-predicted survival (Table 3). Comparing the effects of marker levels on survival, a Kaplan-Meier plot (Fig. 1-6) was constructed for all markers (4th quartile vs. 1st quartile). Only higher level of average CRP level pre- dicts worse survival (Fig. 6). Ferritin and D-dimer do not predict survival differences. For LOSICU prediction, linear regression on log-transformed LOSICU showed that the days that the swab takes to turn negative, bacterial infection, $\mathrm{Cr}$, and $\mathrm{ABG} \mathrm{PH}$ on the day of admission to 
Table 4. Regression for factors determining LOSICU (log LOSICU and predictor variables)

\begin{tabular}{|c|c|c|c|c|}
\hline Variable & $\begin{array}{l}\text { Stand. } \\
\text { coefficients beta }\end{array}$ & $\begin{array}{l}95 \% \text { CI for beta } \\
\text { lower bound }\end{array}$ & $\begin{array}{l}\text { Upper } \\
\text { bound }\end{array}$ & $p$ value \\
\hline Age (years) & -0.025 & -0.010 & 0.008 & 0.830 \\
\hline Gender (male/female) & 0.054 & -0.159 & 0.271 & 0.602 \\
\hline $\mathrm{BMI}, \mathrm{kg} / \mathrm{m}^{2}$ & 0.123 & -0.002 & 0.008 & 0.181 \\
\hline Days turn test negative & 0.239 & 0.001 & 0.013 & 0.029 \\
\hline Diabetes & 0.068 & -0.101 & 0.191 & 0.541 \\
\hline Hypertension & -0.122 & -0.280 & 0.088 & 0.301 \\
\hline CAD & -0.109 & -0.679 & 0.266 & 0.386 \\
\hline Renal failure & 0.015 & -0.263 & 0.294 & 0.912 \\
\hline Outpatient dialysis & 0.209 & -0.086 & 0.537 & 0.153 \\
\hline Immunosuppressed & 0.045 & -0.278 & 0.411 & 0.701 \\
\hline Mechanical ventilation & -0.082 & -0.452 & 0.182 & 0.396 \\
\hline Vasopressers & 0.096 & -0.137 & 0.354 & 0.380 \\
\hline CRRT & 0.128 & -0.070 & 0.243 & 0.273 \\
\hline Bacterial infection & 0.464 & 0.120 & 0.543 & 0.003 \\
\hline Bacteremia & 0.003 & -0.229 & 0.232 & 0.988 \\
\hline Line infection & 0.009 & -0.198 & 0.210 & 0.953 \\
\hline Chloroquine & 0.045 & -0.208 & 0.310 & 0.694 \\
\hline Lopinavir/ritonavir & -0.087 & -0.213 & 0.091 & 0.426 \\
\hline Favipiravir & -0.097 & -0.351 & 0.120 & 0.329 \\
\hline Steroids & 0.087 & -0.164 & 0.371 & 0.442 \\
\hline WBC & 0.017 & -0.015 & 0.017 & 0.878 \\
\hline Ferritin, ng/mL & -0.050 & 0.000 & 0.000 & 0.771 \\
\hline D-dimer, ng/mL & 0.038 & -0.006 & 0.009 & 0.742 \\
\hline Procalcitonin, $\mathrm{ng} / \mathrm{mL}$ & 0.043 & -0.008 & 0.013 & 0.657 \\
\hline $\mathrm{CRP}, \mathrm{mg} / \mathrm{L}$ & -0.095 & -0.001 & 0.000 & 0.404 \\
\hline $\mathrm{Cr}, \mathrm{mg} / \mathrm{dL}$ & -0.338 & -0.090 & -0.009 & 0.017 \\
\hline ABG PH & -0.442 & -2.626 & -0.079 & 0.038 \\
\hline $\mathrm{PCO}_{2}$, Torr & -0.388 & -0.024 & 0.001 & 0.077 \\
\hline $\mathrm{PO}_{2}$, Torr & 0.180 & -0.001 & 0.003 & 0.173 \\
\hline Lactate, $\mathrm{mmol} / \mathrm{L}$ & -0.218 & -0.097 & 0.013 & 0.128 \\
\hline Bicarbonate, mEq/L & 0.124 & -0.018 & 0.035 & 0.532 \\
\hline Magnesium, mg/dL & 0.030 & -0.204 & 0.272 & 0.777 \\
\hline Platelets $\left(10^{3} / \mathrm{mL}\right)$ & -0.011 & -0.001 & 0.001 & 0.921 \\
\hline APACHE 2 score & 0.095 & -0.009 & 0.019 & 0.493 \\
\hline Average ferritin stay in ICU & 0.014 & 0.000 & 0.000 & 0.906 \\
\hline Average D-dimer stay in ICU & 0.143 & -0.010 & 0.027 & 0.348 \\
\hline Average CRP stay in ICU & -0.183 & -0.002 & 0.000 & 0.088 \\
\hline
\end{tabular}

LOSICU, length of stay in the intensive care unit; CRRT, continuous renal replacement therapy; CAD, coronary artery disease; CRP, C-reactive protein.

ICU predicted LOSICU (Table 4). Specific regression for $\log$ LOSICU for CRP in the survivors' group does not predict LOSICU (Fig. 7, 8).

\section{Discussion}

Inflammatory markers are frequently checked. Ferritin and D-dimer on admission do not predict mortality. Only average CRP level for ICU stay predicts mortality.
Using the 4th quartile against the first quartile as a categorical variable, CRP predicts mortality. Ferritin and Ddimers do not. Zhou et al. [9] found that ferritin is significantly elevated in nonsurvivors than survivors, but they did not consider other factors predicting mortality; therefore, their results show the only association of ferritin with mortality. Zhang et al. [10] showed D-dimer on admission greater than $2.0 \mu \mathrm{g} / \mathrm{mL}$ (4-fold increase) predict in-hospital mortality in patients with COVID-19. They also did not adjust for confounding factors by re- 
Fig. 7. Linear regression for LOSICU and CRP on admission. LOSICU, length of stay in the intensive care unit; CRP, C-reactive protein.
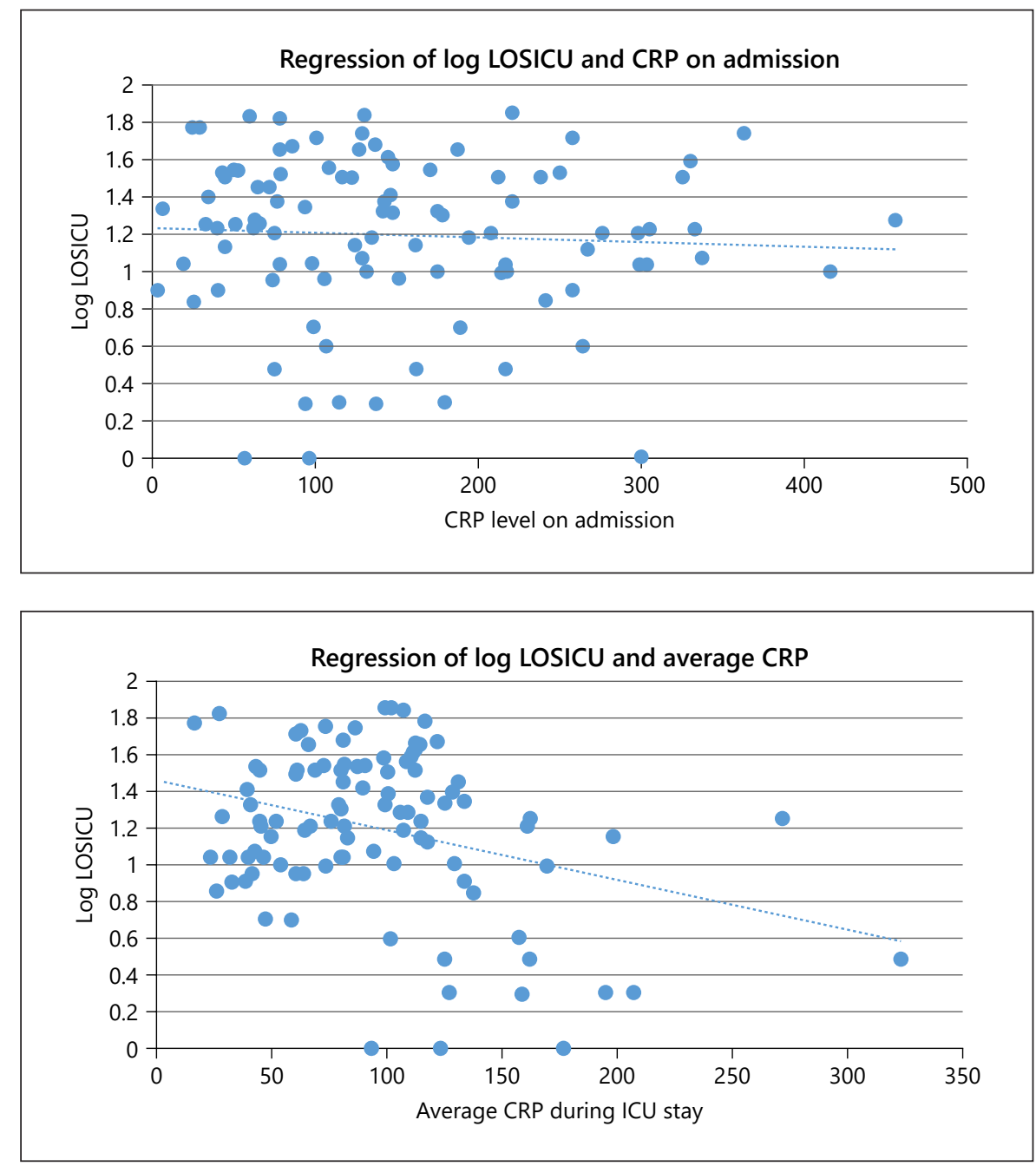

Fig. 8. Linear regression for LOSICU and average CRP during ICU stay. LOSICU, length of stay in the intensive care unit; CRP, C-reactive protein.
Other than ABG PH no factor predicted LOSICU including ferritin, CRP, CAD, and secondary bacterial infection. Moratto et al. [16] found that high ferritin level on admission is associated with prolonged duration of hospitalization. To our knowledge, we are not aware of a study that recorded daily ferritin level and determines the impact of average ferritin level on the length of ICU stay. Moreover, we performed linear regression analysis considering the impact of $>20$ significant confounding factors. This suggests that finding association in other studies may be from different methodology or from not adjusting for other significant variables.

We identify the following limitations. Small sample size and single-center retrospective study may have provided results, not generalizable to other populations. Our extensive daily record of all markers of the whole sample and on each patient provided the dynamic changes dur- 
ing ICU stay within a sample and for each patient therefore it provided more reliable measurements. Extensive including of confounding factors allowed us to estimate the real and actual impact of markers on the outcome.

\section{Conclusion}

Inflammatory markers are elevated in COVID-19 infection. A single level of CRP on admission does not predict outcome although the average CRP level during the stay in ICU predicts survival. Other markers do not predict survival.

\section{Statement of Ethics}

Ethical approval was provided by Emirates Institutional Review Board for COVID-19 Research, DSREC/2020/1324/approved on July 13, 2020.

\section{Conflict of Interest Statement}

None for all authors.

\section{Funding Sources}

The authors did not receive any funding.

\section{Author Contributions}

R.N.: conceived the research idea, proposal writing, data collection, data analysis, and manuscript writing. A.H.: conceived the idea, proposal writing, and review of the final manuscript. N.I.: idea conception and data collection. D.E.: data collection. Z.O., M.S., S.Z., R.A., S.E., C.S., N.A., W.A., M.A., and F.M.: idea conception and data collection. M.H.: data collection and manuscript writing.

\section{References}

1 World Health Organization. Coronavirus disease (COVID-19) pandemic. Geneva: World Health Organization; 2020. p. 310.

2 World Health Organization. Transmission of SARS-CoV-2: implications for infection prevention precautions: scientific brief, 09 July 2020. Geneva: World Health Organization; 2020. No. WHO/2019-Nov/Sci_Brief/Transmission_modes/2020.3.

3 Goh KJ, Kalimuddin S, Chan. KS. Rapid progression to acute respiratory distress syndrome: review of current understanding of critical illness from coronavirus disease 2019 (COVID-19) infection. Ann Acad Med Singapore. 2020;49:108-18.

4 Jaramillo CB, Cevallos D, Sanches-SanMiguel $\mathrm{H}$, Unigarro L, Zalakeviciute R, Gadian N, et al. Clinical, molecular and epidemiological characterization of the SARS-CoV2 virus and the Coronavirus disease 2019 (COVID-19), a comprehensive literature review. Diagn Microbiol Infect Dis. 2020 Sept;98:115094.

5 Chowdhury R, Heng K, Shawon MSR, Goh G, Okonofua D, Ochoa-Rosales C, et al. Dynamic interventions to control COVID-19 pandemic: a multivariate prediction modelling study comparing 16 worldwide countries. Eur J Epidemiol. 2020;35(5):389-99.
6 Konig MF, Powell M, Staedtke V, Bai RY, Thomas DL, Fischer N, et al. Preventing cytokine storm syndrome in COVID-19 using $\alpha-1$ adrenergic receptor antagonists. J Clin Invest. 2020;130(7):3345.

7 Terpos E, Ntanasis-Stathopoulos I, Elalamy I, Kastritis E, Sergentanis TN, Politou M, et al. "Hematological findings and complications of COVID-19”. Am J Hematol. 2020;95:83447.

8 Chen X, Zhao B, Qu Y, Chen Y, Xiong J, Feng $\mathrm{Y}$, et al. Detectable serum SARS-CoV-2 viral load (RNAaemia) is closely correlated with drastically elevated interleukin 6 (IL-6) level in critically ill COVID-19 patients. Clin Infect Dis. 2020;71:1937-42.

9 Zhou F, Ting Y, Du R, Fan G, Liu Y, Liu Z, et al. Clinical course and risk factors for mortality of adult inpatients with COVID-19 in Wuhan, China: a retrospective cohort study. Lancet. 2020;395:1054-62.

10 Zhang L, Yan X, Fan Q, Liu H, Liu X, Liu Z, et al. D-dimer levels on admission to predict in-hospital mortality in patients with Covid-19. J Thromb Haemost. 2020;18(6):13249.
11 Liu F, Li L, Xu M, Wu J, Luo D, Zhu Y, et al. Prognostic value of interleukin-6, C-reactive protein, and procalcitonin in patients with COVID-19. J Clin Virol. 2020;127:104370.

12 Tan C, Huang Y, Shi F, Tan K, Ma Q, Chen Y, et al. "C-reactive protein correlates with computed tomographic findings and predicts severe COVID-19 early. J Med Virol. 2020;92: 856-62.

13 Barman HA, Atici A, Sahin I, Alici G, Aktas Tekin E, Baycan ÖF, et al. Prognostic significance of cardiac injury in COVID-19 patients with and without coronary artery disease. Coron Artery Dis. 2020.

14 Cheng Y, Luo R, Wang K, Zhang M, Wang Z, Dong $L$, et al. Kidney disease is associated with in-hospital death of patients with COVID-19. Kidney Int. 2020;97:829-38.

15 Ruan Q, Yang K, Wang W, Jiang L, Song J. Clinical predictors of mortality due to COVID-19 based on an analysis of data of 150 patients from Wuhan, China. Intensive Care Med. 2020;46(5):846-8.

16 Moratto D, Chiarini M, Giustini V, Serana F, Magro P, Maria Roccaro A, et al. Flow cytometry identifies risk factors and dynamic changes in patients with COVID-19. J Clin Immunol. 2020;40:970-3. 